Article

\title{
The Mechanical Properties and In Vitro Biocompatibility of PM-Fabricated Ti-28Nb-35.4Zr Alloy for Orthopedic Implant Applications
}

\author{
Wei Xu ${ }^{1,+}$, Ming Li ${ }^{1,+}$, Cuie Wen ${ }^{2}$, Shaomin Lv ${ }^{1}$, Chengcheng Liu ${ }^{1}$, Xin Lu ${ }^{1,3,4, *}$ and \\ Xuanhui Qu ${ }^{1,3,4, * \text { (D) }}$ \\ 1 Institute for Advanced Materials and Technology, University of Science and Technology Beijing, \\ Beijing 100083, China; xuweicool@126.com (W.X.); g20159107@xs.ustb.edu.cn (M.L.); \\ lsmleon@163.com (S.L.); liucc1988@163.com (C.L.) \\ 2 School of Engineering, RMIT University, 3083 Melbourne, Australia; cuie.wen@rmit.edu.au \\ 3 Beijing Key Laboratory for Advanced Powder Metallurgy and Particulate Materials, \\ University of Science and Technology Beijing, Beijing 100083, China \\ 4 Beijing Laboratory of Metallic Materials and Processing for Modern Transportation, \\ University of Science and Technology Beijing, Beijing 100083, China \\ * Correspondence: luxin@ustb.edu.cn (X.L.); quxh@ustb.edu.cn (X.Q.); \\ Tel.: +86-10-8237-7286 (X.L.); +86-10-6233-2700 (X.Q.) \\ $\dagger$ These authors contributed equally to this work.
}

Received: 12 March 2018; Accepted: 29 March 2018; Published: 30 March 2018

\begin{abstract}
A biocompatible Ti-28Nb-35.4Zr alloy used as bone implant was fabricated through the powder metallurgy process. The effects of mechanical milling and sintering temperatures on the microstructure and mechanical properties were investigated systematically, before in vitro biocompatibility of full dense Ti-28Nb-35.4Zr alloy was evaluated by cytotoxicity tests. The results show that the mechanical milling and sintering temperatures have significantly effects on the density and mechanical properties of the alloys. The relative density of the alloy fabricated by the atomized powders at $1500{ }^{\circ} \mathrm{C}$ is only $83 \pm 1.8 \%$, while the relative density of the alloy fabricated by the ball-milled powders can rapidly reach at $96.4 \pm 1.3 \%$ at $1500{ }^{\circ} \mathrm{C}$. When the temperature was increased to $1550{ }^{\circ} \mathrm{C}$, the alloy fabricated by ball-milled powders achieve full density (relative density is $98.1 \pm 1.2 \%$ ). The PM-fabricated Ti-28Nb-35.4Zr alloy by ball-milled powders at $1550{ }^{\circ} \mathrm{C}$ can achieve a wide range of mechanical properties, with a compressive yield strength of $1058 \pm 35.1 \mathrm{MPa}$, elastic modulus of $50.8 \pm 3.9 \mathrm{GPa}$, and hardness of $65.8 \pm 1.5 \mathrm{HRA}$. The in vitro cytotoxicity test suggests that the PM-fabricated Ti-28Nb-35.4Zr alloy by ball-milled powders at $1550{ }^{\circ} \mathrm{C}$ has no adverse effects on MC3T3-E1 cells with cytotoxicity ranking of 0 grade, which is nearly close to ELI Ti-6Al-4V or CP Ti. These properties and the net-shape manufacturability makes PM-fabricated Ti-28Nb-35.4Zr alloy a low-cost, highly-biocompatible, Ti-based biomedical alloy.
\end{abstract}

Keywords: Ti-28Nb-35.4 alloy; powder metallurgy; ball milling; mechanical properties; biocompatibility

\section{Introduction}

Metallic biomaterials, which are the materials of choice for orthopedic implants, are fundamental for improve the quality of life and longevity of human beings [1,2]. Many different metallic materials have been used in a variety of applications in the medical field. Specifically, they are used for internal support and biological tissue replacements such as joint replacement, dental roots, orthopedic fixation and stents [3]. The common metals and alloys that are being utilized for biomedical applications include: stainless steels, Co-based alloys, and Ti-based alloys. Ti-based alloys have dominated in the 
human hard tissue repair and dentistry fields due to high strength, low elastic modulus, and excellent in vivo corrosion and biocompatibility [4]. However, despite their attractive performance, there are still challenges facing their application in artificial joints [5]. These concerns are mainly related to bio-toxicity, the need for lower elastic modulus and better mechanical strength. For instance, $\mathrm{Al}$ elements in extra-low interstitial (ELI) Ti-6Al-4V (hereafter all compositions are given in wt \%), Ti-5Al-2.5Fe and Ti-6Al-7Nb [6-8], which is the most widely applied Ti alloy, are considered to be related to some health-related problems, including Alzheimer disease and neuropathy $[9,10]$. In addition, the elastic modulus ( $110 \mathrm{GPa}$ ) of these alloys is still considerably higher than those of the cortical bones ( $30 \mathrm{GPa})$, which results in severe 'stress shielding' for implantation failures [11,12]. Hence, considerable amount of effort has been exeerted to develop Al- and V-free lower-modulus $\beta$-Ti alloys.

Notable examples include the United States Food and Drug Administration (FDA)-approved proprietary alloys of Ti-13Nb-13Zr and Ti-12Mo-6Zr-2Fe and the non-proprietary alloy of Ti-15Mo. In particular, $\mathrm{Ti}-\mathrm{Nb}-\mathrm{Zr}$ alloys have received significant attention due to their excellent mechanical compatibility and biocompatibility [13-16]. The addition of $\mathrm{Nb}$ to Ti can stabilize the $\beta$ phase and results in improved mechanical properties, which also results in improved wear resistance and corrosion resistance $[17,18]$. Furthermore, the addition of $\mathrm{Zr}$ helps in obtaining the solid solution required for achieving the hardness [19,20]. In addition, as reported by references [21,22], the elastic modulus in $\mathrm{Ti}-\mathrm{Nb}$ and Ti- $\mathrm{Zr}$ alloys decreases with an increase in the content of the $\mathrm{Nb}$ and $\mathrm{Zr}$ within certain limits. Based on these results, Wen et al. [23] designed the new Ti-Nb-Zr alloys using the d-electron design method combined with the molybdenum equivalence $\left(\mathrm{Mo}_{\mathrm{eq}}\right)$ and electron-to-atom ratio (e/a) approaches. The results show that the alloys have an excellent combination of mechanical properties and biocompatibility. However, at present these alloys are manufactured by the conventional route (i.e., ingot metallurgy in addition to wrought processing and machining with up to $90 \%$ being scrapped), which leads to a high manufacturing cost. Hence, in order to reduce costs and enhance the utilization rate of materials, the powder metallurgy (PM) technique is introduced. PM is an advanced net-shape technique which particularly suits to large volume production and can reduce processing steps, hence reducing cost [24-27]. It has already been used to synthesize Ti-based alloys by many researchers. For example, Sharma et al. [28] used a powder metallurgy route consisting of mechanical alloys (MA) of the $\mathrm{TiH}_{2}-\mathrm{Nb}$ powder mixture and spark plasma sintering (SPS) to produce Ti-40 mass\% $\mathrm{Nb}$ alloys. Jia et al. [29] successfully obtained the Ti-22Al-25Nb alloy by PM. Mendes et al. [30] produced the alloy Ti-27Nb-13Zr with low Young's modulus by PM using powders produced by the hydride-dehydride (HDH) process.

In this study, the Ti-28Nb-35.4Zr alloy is fabricated by PM in order to obtain Ti-based alloy with excellent mechanical compatibility and biocompatibility in addition to further reducing the manufacturing cost. The effects of sintering temperatures and mechanical milling on density, microstructure and mechanical properties are investigated systematically, before the in vitro biocompatibility of the full dense Ti-28Nb-35.4Zr is evaluated preliminarily. We aimed to establish a necessary understanding of the low-cost PM-fabricated Ti-28Nb-35.4Zr alloy for orthopedic implant applications.

\section{Experimental and Methods}

\subsection{Materials and Sample Preparation}

Atomized Ti-28Nb-35.4Zr powders (purity $\geq 99.9 \%, 75 \leq$ particle size $\leq 150 \mu \mathrm{m}$ ) was supplied by the Wen group (RMIT University, Melbourne, Australia), who fabricated the powders using continuous inert gas atomization without the crucible method. The atomized Ti-28Nb-35.4Zr powders were subjected to ball milling for $30 \mathrm{~min}$ using a three-dimensional vibration ball milling machine (HSVM, Nanjing Chishun Science and Technology Co., Ltd., Nanjing, China). The frequency of the vibration ball milling machine was $1400 \mathrm{r} / \mathrm{min}$, while the ball-to-powder weight ratio was 3:1. 
The materials of the balls and jars were stainless steel and GCr15 bearing steel, respectively. The milling process was carried out in a high-purity argon atmosphere, with $2 \mathrm{wt} \%$ stearate used as the process control agent (PCA). Atomized powder (AP) and ball-milled powder (BMP) were cold-pressed into cylindrical compacts under $450 \mathrm{MPa}$. Then isothermal sintering was carried out in the argon (Ar) protection environment and implemented in two steps. Specimens were initially heated to $1000{ }^{\circ} \mathrm{C}$ for $2 \mathrm{~h}$ at $5{ }^{\circ} \mathrm{C} / \mathrm{min}$, before being heated at $2{ }^{\circ} \mathrm{C} / \mathrm{min}$ to six different temperatures between $1200{ }^{\circ} \mathrm{C}$ and $1550{ }^{\circ} \mathrm{C}$ for $2 \mathrm{~h}$. This was followed by furnace cooling to room temperature to obtain samples.

\subsection{Materials Characterization}

The density was measured by the Archimedes method and the relative density was calculated by the following formula:

$$
\text { Relative density }=\text { the density/the theoretical density }
$$

where the theoretical density is $6.36 \mathrm{~g} / \mathrm{cm}^{3}$. The hardness was carried out using the HDI-1875 Rockwell hardness tester. Five points were measured, before the average value was calculated. X-ray diffraction (XRD) was performed using a Dmax-RB X-ray diffractometer $(\mathrm{Cu} \mathrm{K} \alpha, \lambda=0.15406 \mathrm{~nm}$, Rigaku, Tokyo, Japan). A JSM-6510V (JEOL, Tokyo, Japan) scanning electron microscope (SEM) was used to analyze the powder morphology of the received atomized powders and ball-milled powders and sintered microstructure. Compression specimens with a gauge size $(\varphi)$ of $3 \mathrm{~mm} \times 5 \mathrm{~mm}$ were fabricated by electric discharge machining and the specimen surface was polished with $\mathrm{SiC}$ papers. The compression test was performed on an Instron machine (Instron, Boston, MA, USA) at the strain rate of $2 \times 10^{-3} \mathrm{~s}^{-1}$ at room temperature. The compressive yield strength and elastic modulus were calculated from the engineering stress strain curves.

\subsection{In Vitro Biocompatibility Testing}

Cytotoxicity tests were carried out with murine osteoblast cells (MC3T3-E1) to examine the in vitro biocompatibility of the Ti-28Nb-35.4Zr alloy. For comparison, the cast ELI Ti-6Al-4V and CP-Ti were studied simultaneously. The cells were cultured in Dulbecco's modified Eagle's medium (DMEM, Shanghai solarbio Bioscience and Technology Co., Ltd., Shanghai, China) containing 10\% fetal bovine serum (FBS), $100 \mathrm{U} / \mathrm{mL}$ penicillin, and $100 \mu \mathrm{g} / \mathrm{mL}$ streptomycin at $37^{\circ} \mathrm{C}$ under a humidified atmosphere of air containing $5 \% \mathrm{CO}_{2}$. The metal samples were cut into discs of $10 \mathrm{~mm}$ in diameter and $1 \mathrm{~mm}$ in thickness via electric discharge machining, before the surface was polished with $\mathrm{SiC}$ papers (grit 400 down to 5000). After this, the samples were cleaned ultrasonically and sterilized for further use.

In the cytotoxicity test, the extracts were obtained based on the international standard ISO 10993-5 [31]. The cells were incubated by an extraction medium in 96-well plates at the density of 5000 cells per $100 \mu \mathrm{L}$. At the desired times (day 1, day 2 and day 3), cells were observed by the optical microscope (LEXT OLS4000, Olympus, Tokyo, Japan), while the $10 \mu \mathrm{L}$ MTT solution (Shanghai solarbio Bioscience and Technology Co., Ltd., Shanghai, China) was added to each well and were incubated for $4 \mathrm{~h}$. After this, $100 \mu \mathrm{L}$ of dimethyl sulfoxide (DMSO, Shanghai solarbio Bioscience and Technology Co., Ltd., Shanghai, China) was added to each well, before being incubated for a further $5 \mathrm{~min}$. The absorbance was recorded by a multimode detector on a Synergy HT (BioTek, Winooski, VT, USA) at a wavelength of $570 \mathrm{~nm}$. The cell viability ratio (CVR) was calculated by the formula as follows:

$$
C V R=\left(O D_{570 \mathrm{~nm}} \text { in experimental extract } / O D_{570 \mathrm{~nm}} \text { in control extract }\right) \times 100 \%
$$

Based on the international standard ISO 10993-5 [31], the cytotoxic level was divided into six groups: 0: $\geq 100 \%$; I: 75-99\%; II: 50-74\%; III: 25-49\%; IV: 1-24\%; V: $\leq 1 \%$. Cell viability ratio 
were analyzed using one-way analysis of variance (ANOVA, $\mathrm{P}<0.05$ ) followed by the Tukey honestly significant difference (HSD) post-hoc test. $\mathrm{P}<0.05$ was considered to be statistically significant.

\section{Results and Discussion}

\subsection{Raw Powder Characterization}

Figure 1 depicts the representative SEM micrographs of atomized and ball-milled powders. It can be seen that the atomized powders (Figure 1a) have a typical spherical shape. The particle size of the powders varies from 30.2 to $160.5 \mu \mathrm{m}$ with an average particles size of approximately $80.5 \mu \mathrm{m}$. The morphology of the Ti-Nb-Zr particles after $30 \mathrm{~min}$ of ball milling is shown in Figure $1 \mathrm{~b}$. The particle size of the ball-milled powders varies from 5.1 to $30.5 \mu \mathrm{m}$ with an average particle size of approximately $15.2 \mu \mathrm{m}$. The shape of the powders becomes irregular, which makes further powder treatment easier (green compaction) as irregular powder particles have higher compressibility and green strength [32].
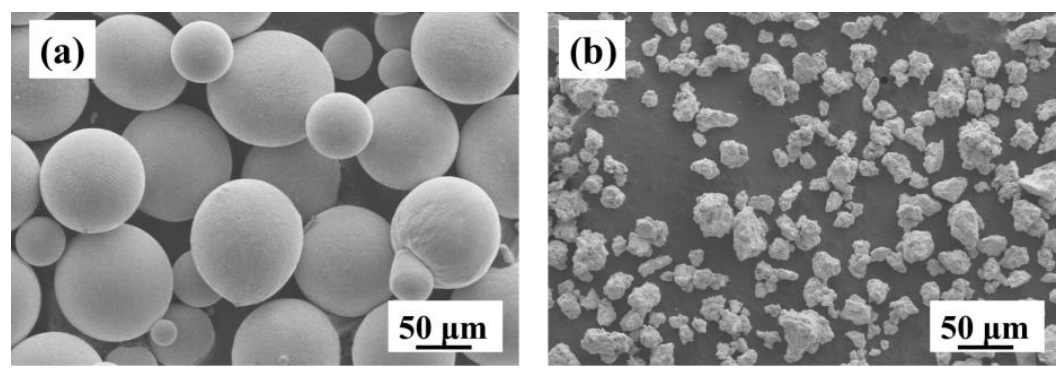

Figure 1. SEM images $(800 \times)$ of the powders: (a) Atomized powders; and (b) Ball-milled powders.

Figure 2 shows the XRD patterns of atomized and ball-milled powders. It can be seen that atomized powders consist of a single $\beta-\mathrm{Ti}$, while the ball-milled powders consist of $\beta-\mathrm{Ti}$ and $\mathrm{TiO} 2$. $\mathrm{TiO}_{2}$ mainly emerges because there is some oxygen introduced during the process of ball milling. In addition, compared with the atomized powders, the diffraction spectrums of the ball-milled powders shows an obvious broadening and moves to low angle, which is associated with the reduction in grain size, increase in lattice distortion and instrumental effects [33].

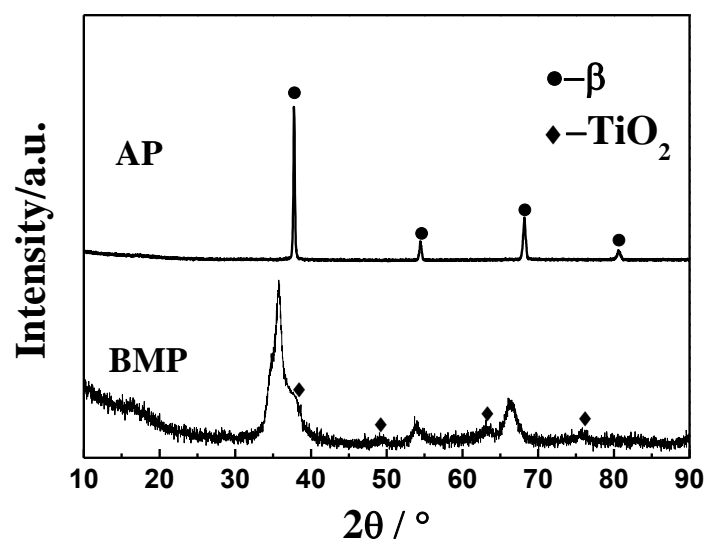

Figure 2. XRD patterns of atomized and ball-milled powders.

\subsection{As-Sintered Density}

Figure 3 shows the variation in relative density of samples with respect to sintering temperatures and powders. The relative density strongly depends on both sintering temperatures and powders. For the atomized powder, with an increase in the sintering temperature the relative density of the alloys increases gradually, but it is difficult to achieve a high relative density. The relative density of 
the alloy sintered at $1500{ }^{\circ} \mathrm{C}$ is only $83.1 \pm 1.8 \%$. Compared to the samples fabricated by atomized powder, the relative density of the samples fabricated by milled powder at $1500{ }^{\circ} \mathrm{C}$ rapidly increases to $96.4 \pm 1.3 \%$. When the sintering temperature increases to $1550{ }^{\circ} \mathrm{C}$, the relative density of the alloy reaches $98.1 \pm 1.2 \%$.

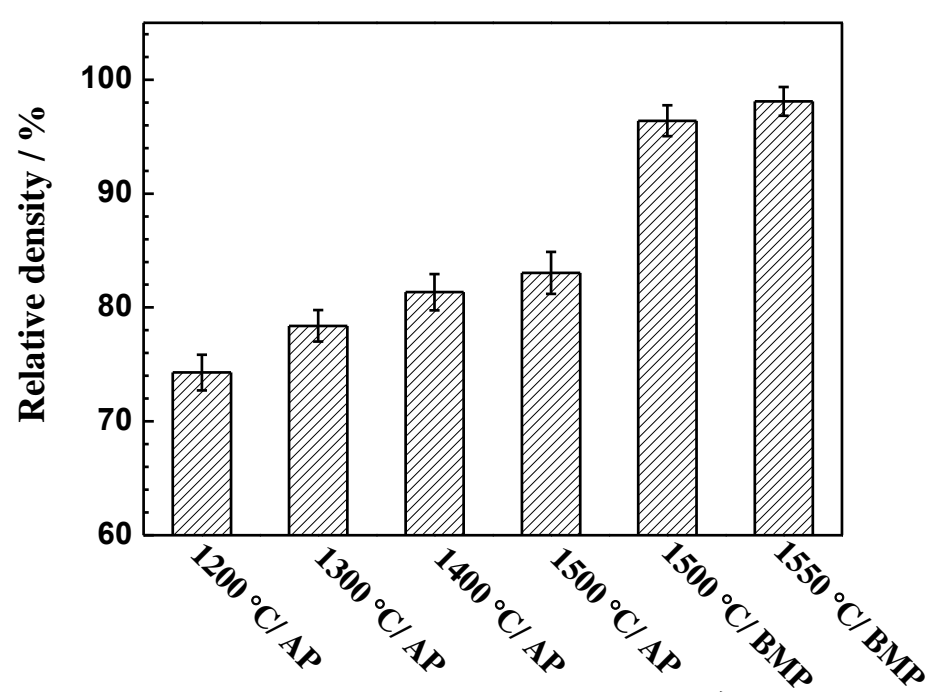

Figure 3. Relative density of Ti-28Nb-35.4Zr alloy prepared with different sintering temperatures and powders.

Figure 4 shows the optional images of Ti-28Nb-35.4Zr prepared with different sintering temperatures and powders. As shown in Figure $4 a-d$, the porosity of the samples fabricated by atomized powders decreases gradually with an increase in the sintering temperature. However, there are many pores on the surface of the samples even when they are sintered at $1500{ }^{\circ} \mathrm{C}$. As shown by Figure $4 \mathrm{e}, \mathrm{f}$, the porosity of alloy prepared by milled powder reduces significantly, while the alloy becomes close to full density when sintered at $1550{ }^{\circ} \mathrm{C}$. This is mainly associated with the sintering process of powder particles. After milling, the average particle sizes of the powders become smaller and hence, the powders have a high interface energy, which makes the sintering neck form more easily. Therefore, compared with the samples fabricated by atomized powder, the alloys prepared by milled powders have a higher density and therefore higher relative density.
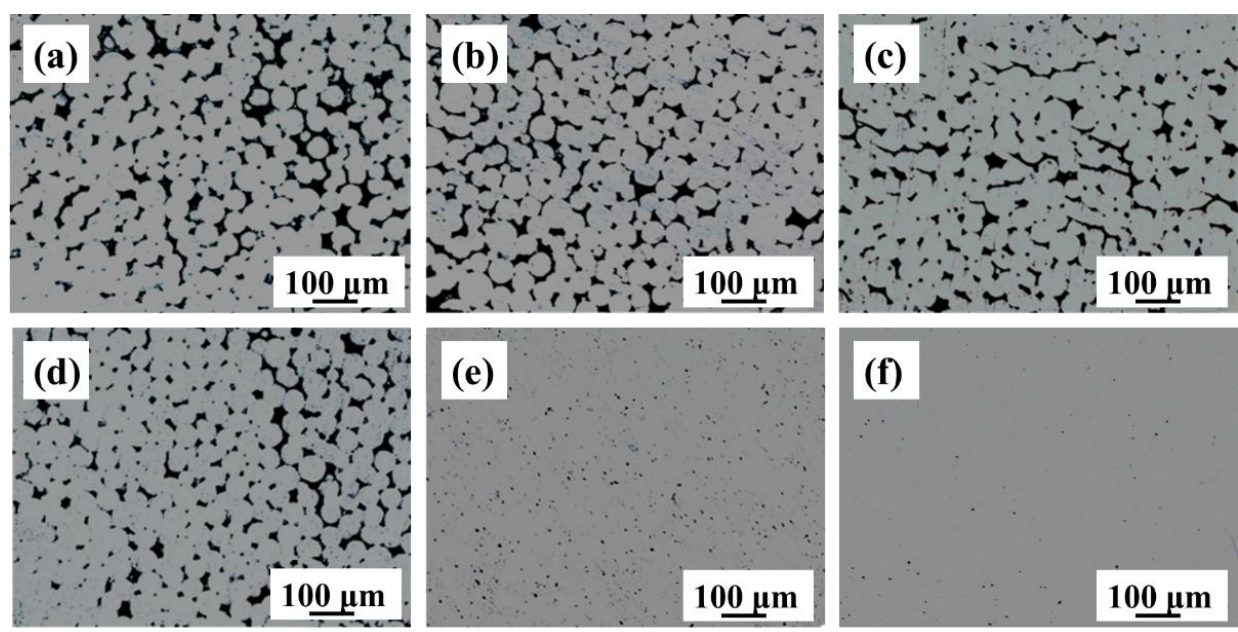

Figure 4. Optical images of Ti-28Nb-35.4Zr prepared with different sintering temperatures and raw powders: (a) $1200{ }^{\circ} \mathrm{C} / \mathrm{AP}$; (b) $1300{ }^{\circ} \mathrm{C} / \mathrm{AP}$; (c) $1400{ }^{\circ} \mathrm{C} / \mathrm{AP}$; (d) $1500{ }^{\circ} \mathrm{C} / \mathrm{AP}$; (e) $1500{ }^{\circ} \mathrm{C} / \mathrm{BMP}$ and (f) $1550{ }^{\circ} \mathrm{C} / \mathrm{BMP}$. 


\subsection{As-Sintered Microstructure}

Figure 5 shows the XRD patterns of Ti-28Nb-35.4Zr alloy fabricated by different powders at different sintering temperature. It can be seen that there is no significant difference of XRD patterns of $\mathrm{Ti}-28 \mathrm{Nb}-35.4 \mathrm{Zr}$ alloy fabricated by different powders and sintering temperatures. The clear diffraction peaks suggest that the samples all have similar phase compositions and mainly consist of single $\beta$ phases.

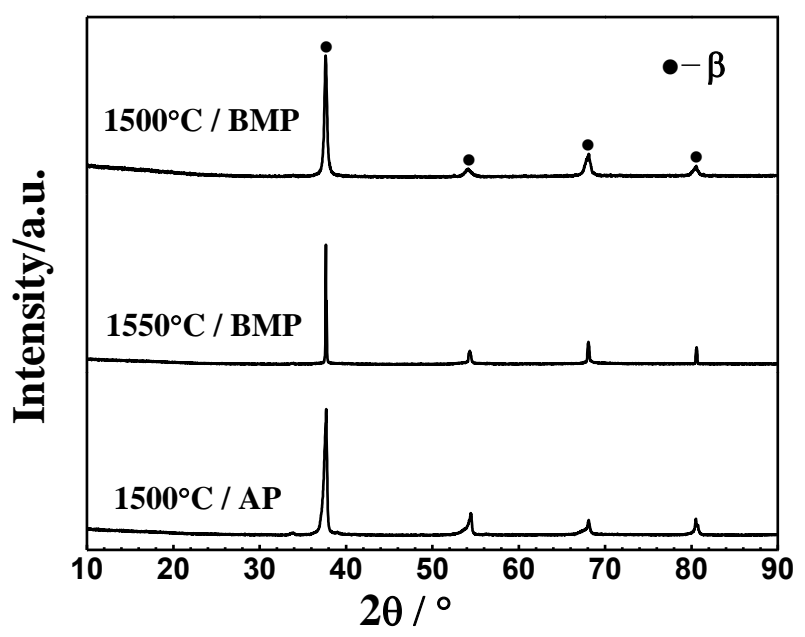

Figure 5. XRD patterns of Ti-28Nb-35.4Zr alloy prepared with different temperatures and powders.

Figure 6 displays the SEM micrographs of Ti-28Nb-35.4Zr alloy samples sintered at different temperatures with different powders, which was taken under $800 \times$ magnification. It can be seen that some pores exist in the alloy fabricated by the atomized powder at $1500^{\circ} \mathrm{C}$ and the original powder particle boundaries can be observed clearly. However, the alloy prepared by milled powder at $1500{ }^{\circ} \mathrm{C}$ has a few pores, while the alloy becomes nearly fully dense with no obvious pores when the sintering temperature increases to $1550^{\circ} \mathrm{C}$. In addition, as shown in Figure $6 \mathrm{~b}, \mathrm{c}$, the samples fabricated by the milled powder show a similar microstructure, which is consistent with the XRD results. Both samples consist of a single $\beta$ phase and the average grain size is about $100 \pm 10 \mu \mathrm{m}$.

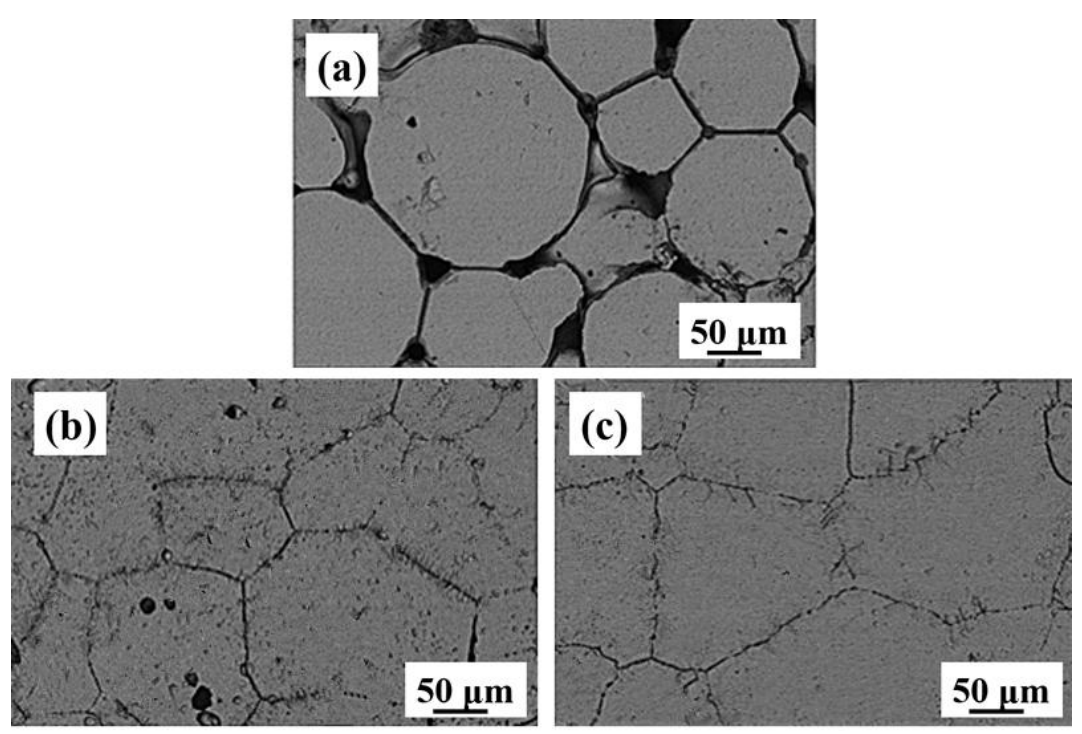

Figure 6. SEM images $(800 \times)$ of Ti-28Nb-35.4Zr alloy prepared with different sintering temperatures and powders: (a) $1500{ }^{\circ} \mathrm{C} / \mathrm{AP}$; (b) $1500{ }^{\circ} \mathrm{C} / \mathrm{BMP}$ and (c) $1550{ }^{\circ} \mathrm{C} / \mathrm{BMP}$. 


\subsection{Room-Temperature Mechanical Properties}

Figure 7 shows compressive engineering stress-strain curves of the Ti-28Nb-35.4Zr alloy fabricated by different powders at different sintering temperatures. As shown in Figure 7, the alloys exhibit similar stress-strain behavior and no fracture was observed during their compression process, demonstrating that the alloys exhibit considerable elastic-plastic deformation ability. Compression tests were stopped after reaching a strain value of about $50 \%$.

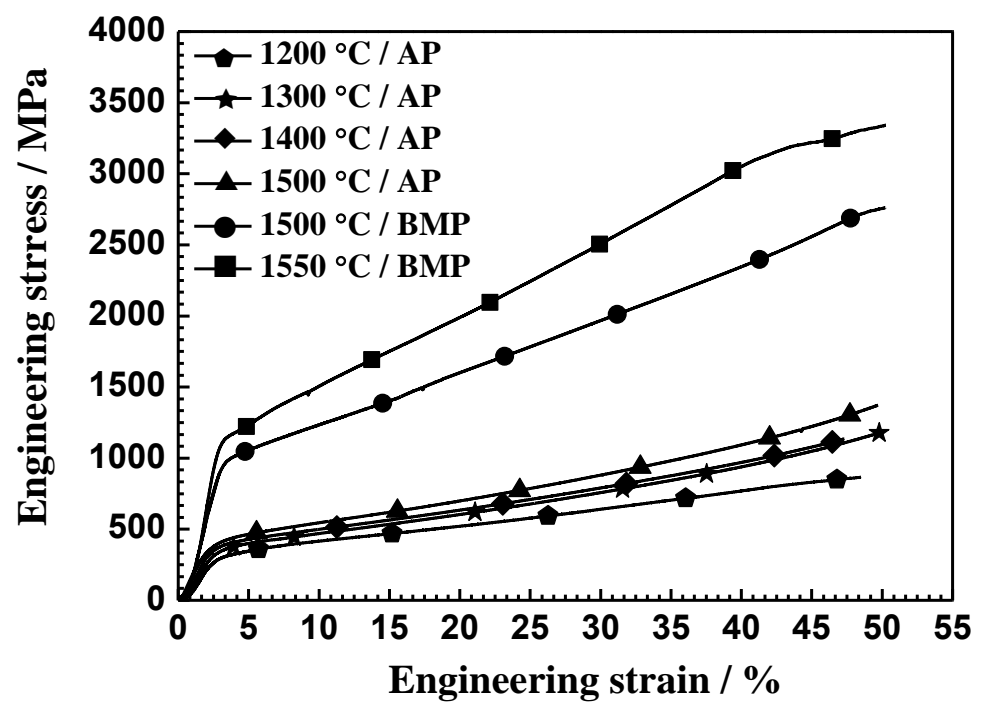

Figure 7. Compressive stress-strain curves of Ti-28Nb-35.4Zr alloy prepared with different sintering temperatures and powders.

The compressive yield strength, elastic modulus and hardness of Ti-28Nb-35.4Zr alloy fabricated by different powders at different sintering temperatures are shown in Figure 8. The hardness, compressive yield strength and elastic modulus of the Ti-28Nb-35.4Zr alloy fabricated atomized powder generally increase with an increase in the sintering temperature, which were in the range of 27.3-39.2 HRA, 273-332 MPa and 15.6-24.0 GPa, respectively. Compared with the alloy fabricated by the atomized powder, the mechanical properties of the alloy prepared by milled powder are significantly improved. The hardness of the alloy sintered at $1550{ }^{\circ} \mathrm{C}$ reaches $65.8 \pm 1.5 \mathrm{HRA}$ (Figure 8a) while the elastic modulus and compressive yield strength is $50.8 \pm 3.9 \mathrm{GPa}$ and $1058 \pm 35.1 \mathrm{MPa}$ (Figure $8 \mathrm{~b}$ ), respectively. This is superior to the mechanical properties fabricated by the cold-crucible levitation melting (compressive yield strength of $730 \mathrm{MPa}$ [23]). The improvement in the compressive yield strength of the BMP sintered samples stems from two reasons. The first reason is that there is some oxygen introduced during the process of ball milling, which can also can be seen from the powders XRD results for the powders. In addition, compared with the samples fabricated by cold-crucible levitation melting, the PM-fabricated samples have smaller grains, uniform microstructure and less defects, which can also improve the strength. 

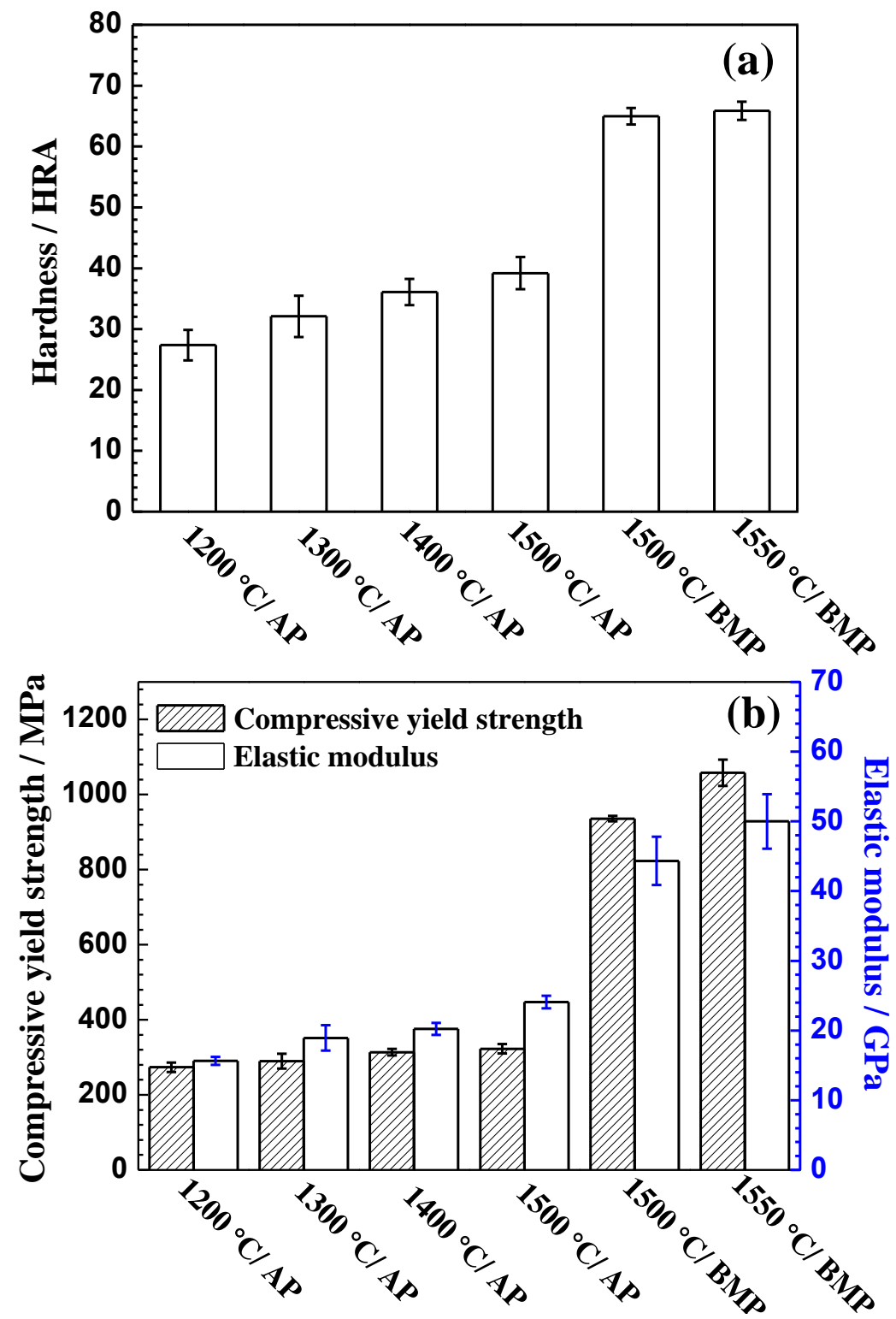

Figure 8. Mechanical properties of Ti-28Nb-34.5Zr alloy prepared with different sintering temperatures and powders: (a) Hardness; (b) Compressive elastic modulus and yield strength.

\subsection{In Vitro Biocompatibility}

In vitro biocompatibility of the Ti-28Nb-35.4Zr alloy sintered at $1550{ }^{\circ} \mathrm{C}$ by the milled powder was evaluated by cell tests. The CVR was calculated by Equation (2). The control group has a CVR of $100 \%$, which is accepted as a reference for determining the cell viability radio of samples [34]. Figure 9 shows the results of CVR using MC3T3-E1 cells grown in Ti-28Nb-35.4Zr alloy, ELI Ti-6Al-4V and CP-Ti extracts for 1, 2 and 3 days. It can be seen that the average CVR value of all the experimental alloys was above $99 \%$. The Ti-28Nb-35.4Zr alloy exhibits a slightly higher average CVR value than ELI Ti-6Al-4V while was similar to CP Ti. However there were no statistically significant differences among them ( $\mathrm{P}>0.05)$. According to ISO 10993-5 [31], the cytotoxicity grade of Ti-28Nb-35.4Zr alloy and CP Ti is 0-I grade while that of ELI Ti-6Al-4V is 0-I grade. Consequently, the PM-fabricated Ti-28Nb-35.4Zr alloy shows good in vitro biocompatibility to MC3T3-E1 cells. 


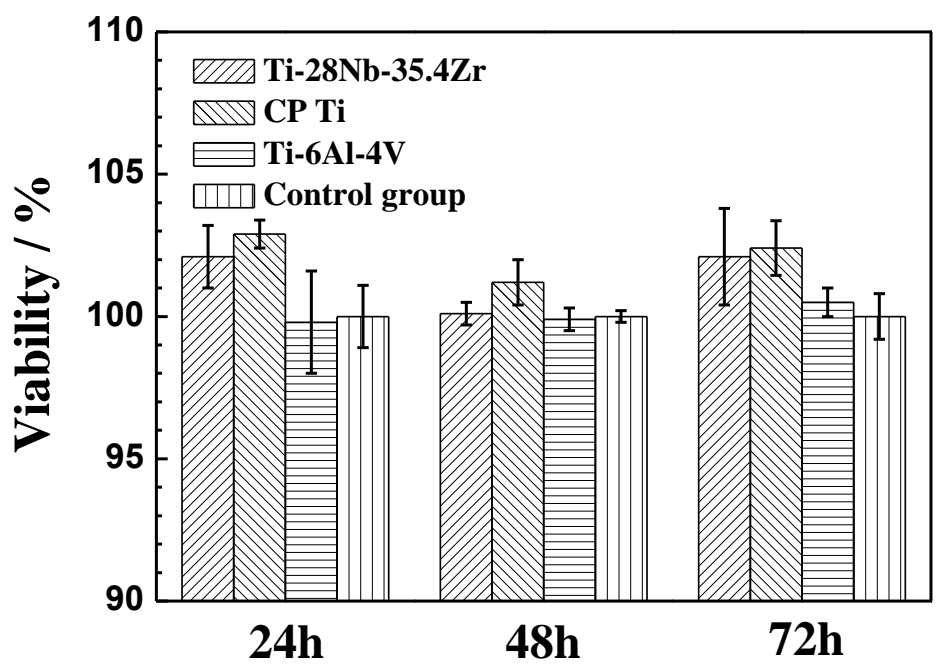

Figure 9. MTT result of MC3T3-E1 cells cultured with extracts of $\mathrm{Ti}-28 \mathrm{Nb}-35.4 \mathrm{Zr}, \mathrm{CP}$ Ti and ELI Ti-6Al-4V.

Figure 10 displays the number and morphology of MC3T3-E1 cells cultured with extracts of Ti-28Nb-35.4Zr ELI Ti-6Al-4V and CP-Ti for different periods ( 1 day, 2 days and 3 days). It can be seen that the morphologies of all cells are similar for different periods. After a 1-day culture, cells are basically adhered to the well and the shape is spindle. With a prolonged culture time, cells cultured by different Ti alloys become denser and stretched, although there are no significantly changes in MTT.
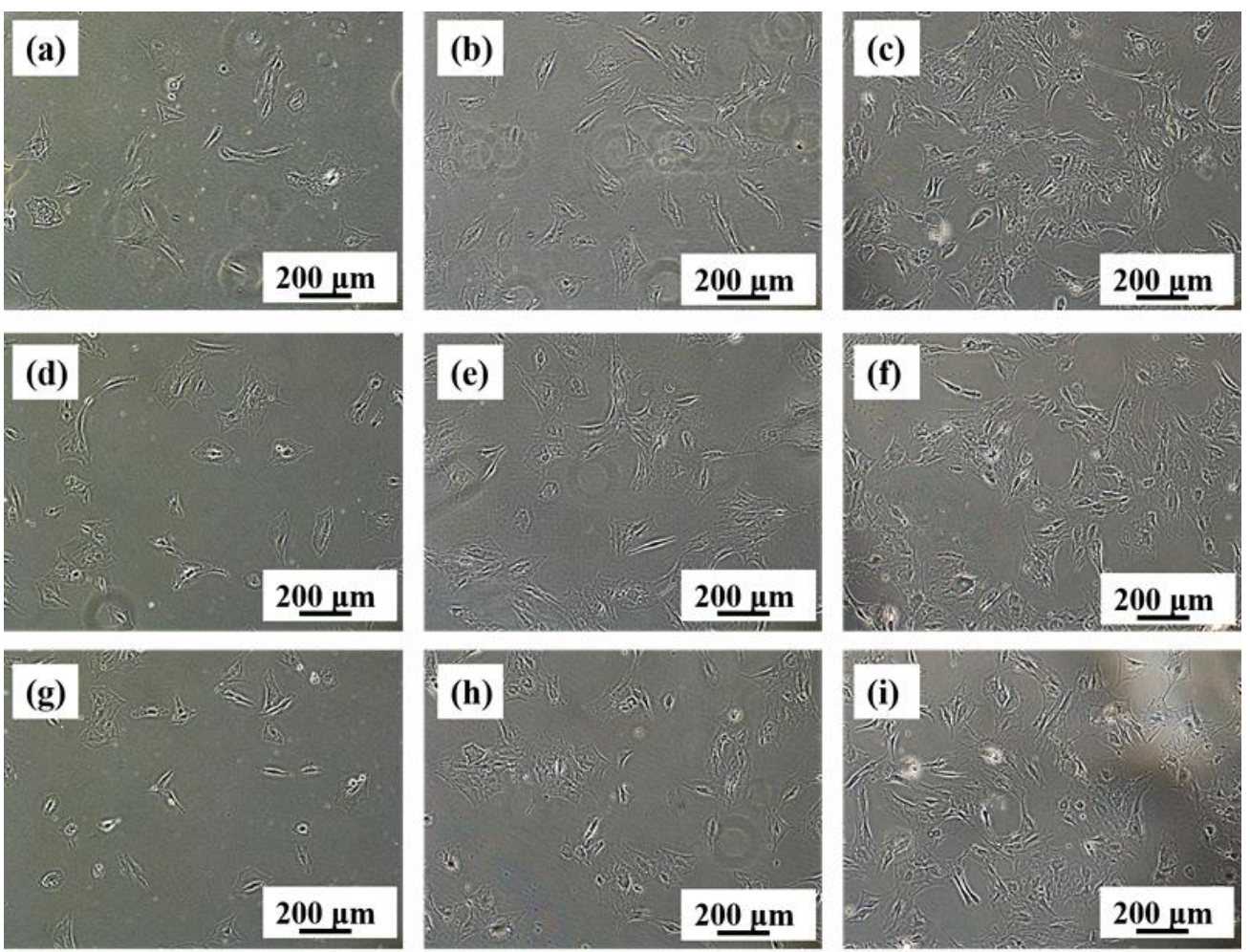

Figure 10. The number and morphology of MC3T3-E1 cells cultured with extracts of Ti-28Nb-35.4Zr ((a): 24 h; (b): 48 h; (c): 72 h), CP Ti ((d): 24 h; (e): 48 h; (f): 72 h) and ELI Ti-6Al-4V ((g): 24 h; (h): 48 h; (i): $72 \mathrm{~h})$. 
The in vitro biocompatibility of an implant lies not only in the toxicity of its alloys elements, but also in its corrosion resistance. Ti-Nb-Zr alloys are formed by the solid solutions of pure $\mathrm{Ti}, \mathrm{Nb}$ and $\mathrm{Zr}$, and maintain a high corrosion resistance and low toxicity [35]. Further, the corrosion resistance of Ti-Nb-Zr alloys is superior to that of CP Ti and ELI Ti-6Al-4V [36]. Spontaneously formed oxides, made up of $\mathrm{TiO}_{2}, \mathrm{Nb}_{2} \mathrm{O}_{3}$ and $\mathrm{Zr}_{2} \mathrm{O}_{3}$, will provide a bio-inert layer in aggressive body fluids [37]. The enrichment of $\mathrm{TiO}_{2}, \mathrm{Nb}_{2} \mathrm{O}_{3}$ and $\mathrm{Zr}_{2} \mathrm{O}_{3}$ on the surface suppressed the dissolution of $\mathrm{Ti}, \mathrm{Zr}$ and $\mathrm{Nb}$ as ions. Hence, the Ti-28Nb-35.4Zr alloys show high cell viability during the MTT assays. Coupled with the low elastic modulus, high compressive yield strength and net-shape manufacturability, it thus suggests that PM-fabricated Ti-28Nb-35.4Zr alloy may hold promise for the development of next class of low-cost, highly-biocompatible, Ti-based biomedical alloys.

\section{Conclusions}

(1) Ti-28Nb-35.4Zr alloy with a high relative density and uniform microstructure can be obtained from milled powder via PM. After milling, the average particle sizes of powders was $15.2 \mu \mathrm{m}$, and when sintered at $1550{ }^{\circ} \mathrm{C}$, the relative density reaches $98.1 \pm 1.2 \%$. The alloy fabricated by milled powders at $1550{ }^{\circ} \mathrm{C}$ is characterized by the single $\beta$ phase.

(2) The alloys fabricated by the ball-milled powder at $1550{ }^{\circ} \mathrm{C}$ can achieve a high mechanical properties with the compressive yield strength of $1058 \pm 35.1 \mathrm{MPa}$, the elastic modulus of $50.8 \pm 3.9 \mathrm{GP}$, and the hardness of $65.8 \pm 1.5 \mathrm{HRA}$. This is superior to the mechanical properties fabricated by the cold-crucible levitation melting technique.

(3) From in vitro cytotoxicity tests, the Ti-28Nb-35.4Zr alloy fabricated by milled powder at $1550{ }^{\circ} \mathrm{C}$ has no adverse effects on cell proliferation, and the cytotoxicity level is ranked as 0 grade, which is similar to the existing biomedical materials of CP Ti or ELI Ti-6Al-4V.

(4) Based on its demonstrated net-shape manufacturability by PM, high compressive yield strength, low elastic modulus and excellent in vitro biocompatibility, the PM-fabricated Ti-28Nb-35.4Zr can be considered as an attractive orthopedic implant alloy.

Acknowledgments: This research work is supported by Fundamental Research Funds for the Central Universities (FRF-GF-17-B39).

Author Contributions: Wei $\mathrm{Xu}$, Ming Li and Xin Lu conceived and designed the experiments; Wei Xu and Ming Li performed the experiments; Wei Xu and Ming Li analyzed the data and wrote the paper; Chengcheng Liu, Shaomin Lv, Cuie Wen, Xin Lu and Xuanhui Qu revised the manuscript; all authors discussed and approved the final manuscript.

Conflicts of Interest: The authors declare no conflict of interest.

\section{References}

1. Okulov, I.V.; Volegov, A.S.; Attar, H.; Bönisch, M.; Ehtemam-Haghighi, S.; Calin, M.; Eckert, J. Composition optimization of low modulus and high-strength TiNb-based alloys for biomedical applications. J. Mech. Behav. Biomed. 2016, 65, 866-871. [CrossRef] [PubMed]

2. Attar, H.; Bönisch, M.; Calin, M.; Zhang, L.C.; Scudino, S.; Eckert, J. Selective laser melting of in situ titanium-titanium boride composites: Processing, microstructure and mechanical properties. Acta Mater. 2014, 76, 13-22. [CrossRef]

3. Dai, N.W.; Zhang, J.X.; Chen, C.; Zhang, L.C. Heat treatment degrading the corrosion resistance of selective laser melted Ti-6Al-4V alloy. J. Electrochem. Soc. 2017, 164, C428-C434. [CrossRef]

4. Biesiekierski, A.; Lin, J.; Li, Y.; Ping, D.H.; Yamabe-Mitarai, Y.; Wen, C.E. Investigations into Ti-(Nb,Ta)-Fe alloys for biomedical applications. Acta Biomater. 2016, 32, 336-347. [CrossRef] [PubMed]

5. Ehtemam-Haghighi, S.; Prashanth, K.G.; Attar, H.; Chaubey, A.K.; Cao, G.H.; Zhang, L.C. Evaluation of mechanical and wear properties of Ti-xNb-7Fe alloys designed for biomedical applications. Mater. Des. 2016, 111, 592-599. [CrossRef]

6. Lu, S.L.; Qian, M.; Tang, H.P.; Yan, M.; Wang, J.; StJohn, D.H. Massive transformation in Ti-6Al-4V additively manufactured by selective electron beam melting. Acta Mater. 2016, 104, 303-311. [CrossRef] 
7. Siqueira, R.P.; Sandim, H.R.Z.; Hayama, A.O.F.; Henriques, V.A.R. Microstructural evolution during sintering of the blended elemental Ti-5Al-2.5Fe alloy. J. Alloys Compd. 2009, 476, 130-137. [CrossRef]

8. Polyakova, V.V.; Semenova, I.P.; Polyakov, A.V.; Magomedova, D.K.; Huang, Y.; Langdon, T.G. Influence of grain boundary misorientations on the mechanical behavior of a near- $\alpha$ Ti-6Al-7Nb alloy processed by ECAP. Mater. Lett. 2017, 190, 256-259. [CrossRef]

9. Flaten, T.P. Aluminium as a risk factor in Alzheimer's disease, with emphasis on drinking water. Brain Res. Bull. 2001, 55, 187-196. [CrossRef]

10. Lima, P.D.; Vasconcellos, M.C.; Montenegro, R.C.; Bahia, M.O.; Costa, E.T.; Antunes, L.M.; Burbano, R.R. Genotoxic effects of aluminum, iron and manganese in human cells and experimental systems: A review of the literature. Hum. Exp. Toxicol. 2011, 30, 1435-1444. [CrossRef] [PubMed]

11. Wang, X.J.; Xu, S.Q.; Zhou, S.W.; Xu, W.; Leary, M.; Choong, P.; Qian, M.; Brandt, M.; Xie, Y.M. Topological design and additive manufacturing of porous metals for bone scaffolds and orthopaedic implants: A review. Biomaterials 2016, 83, 127-141. [CrossRef] [PubMed]

12. Xu, W.; Lu, X.; Zhang, B.; Liu, C.C.; Lv, S.M.; Yang, S.D.; Qu, X.H. Effects of Porosity on Mechanical Properties and Corrosion Resistances of PM-Fabricated Porous Ti-10Mo Alloy. Metals 2018, 8, 188. [CrossRef]

13. Lee, T.; Park, K.T.; Dong, J.L.; Jeong, J.; Sang, H.O.; Kim, H.S.; Park, C.H.; Lee, C.S. Microstructural evolution and strain-hardening behavior of multi-pass caliber-rolled Ti-13Nb-13Zr. Mater. Sci. Eng. A 2015, 648, 359-366. [CrossRef]

14. Niinomi, M. Fatigue performance and cyto-toxicity of low rigidity titanium alloy, Ti-29Nb-13Ta-4.6Zr. Biomaterials 2003, 24, 2673-2683. [CrossRef]

15. Zhang, L.C.; Klemm, D.; Eckert, J.; Hao, Y.L.; Sercombe, T.B. Manufacture by selective laser melting and mechanical behavior of a biomedical Ti-24Nb-4Zr-8Sn alloy. Scr. Mater. 2011, 65, 21-24. [CrossRef]

16. Niinomi, M.; Nakai, M.; Hieda, J. Development of new metallic alloys for biomedical applications. Acta Biomater. 2012, 8, 3888-3903. [CrossRef] [PubMed]

17. Zhou, F.Y.; Wang, B.L.; Qiu, K.J.; Lin, W.J.; Li, L.; Wang, Y.B.; Nie, F.L.; Zheng, Y.F. Microstructure, corrosion behavior and cytotoxicity of Zr-Nb alloys for biomedical application. Mater. Sci. Eng. C 2012, 32, 851-857. [CrossRef]

18. Li, S.J.; Yang, R.; Li, S.; Hao, Y.L.; Cui, Y.Y.; Niinomi, M.; Guo, Z.X. Wear characteristics of Ti-Nb-Ta-Zr and Ti-6Al-4V alloys for biomedical applications. Wear 2004, 257, 869-876. [CrossRef]

19. Kobayashi, E.; Ando, M.; Tsutsumi, Y.; Doi, H.; Yoneyama, T.; Kobayashi, M.; Hanawa, T. Inhibition effect of zirconium coating on calcium phosphate precipitation of titanium to avoid assimilation with bone. Mater. Trans. 2007, 48, 301-306. [CrossRef]

20. Hanawa, T.; Okuno, O.; Hamanaka, H. Compositional change in surface of Ti-Zr alloys in artificial bioliquid. J. Jpn. Inst. Met. Mater. 1992, 56, 1168-1173. [CrossRef]

21. Lee, C.M.; Ju, C.P.; Lin, J.H.C. Structure-property relationship of cast Ti-Nb alloys. J. Oral Rehabil. 2002, 29, 314-322. [CrossRef] [PubMed]

22. Ho, W.F.; Chen, W.K.; Wu, S.C.; Hsu, H.C. Structure, mechanical properties, and grindability of dental Ti-Zr alloys. J. Mater. Sci. 2008, 19, 3179-3186. [CrossRef]

23. Ozan, S.; Lin, J.X.; Li, Y.C.; Ipek, R.; Wen, C.E. Development of Ti-Nb-Zr alloys with high elastic admissible strain for temporary orthopedic devices. Acta Biomater. 2015, 20, 176-187. [CrossRef] [PubMed]

24. Pattanayak, D.K.; Matsushita, T.; Doi, K.; Takadama, H.; Nakamura, T.; Kokubo, T. Effects of oxygen content of porous titanium metal on its apatite-forming ability and compressive strength. Mater. Sci. Eng. C 2009, 29, 1974-1978. [CrossRef]

25. Niu, W.J.; Bai, C.G.; Qiu, G.B.; Wang, Q. Processing and properties of porous titanium using space holder technique. Mater. Sci. Eng. C 2009, 506, 148-151. [CrossRef]

26. Liu, Y.; Chen, L.F.; Tang, H.P.; Liu, C.T.; Liu, B.; Huang, B.Y. Design of powder metallurgy titanium alloys and composites. Mater. Sci. Eng. A 2006, 418, 25-35. [CrossRef]

27. Kipouros, G.J.; Caley, W.F.; Bishop, D.P. On the advantages of using powder metallurgy in new light metal alloy design. Metall. Mater. Trans. A 2006, 37, 3429-3436. [CrossRef]

28. Sharma, B.; Vaipai, S.K.; Ameyama, K. Microstructure and properties of beta Ti-Nb alloy prepared by powder metallurgy route using titanium hydride powder. J. Alloys Compd. 2012, 656, 978-986. [CrossRef]

29. Jia, J.; Zhang, K.; Liu, L.; Wu, F.Y. Hot deformation behavior and processing map of a powder metallurgy Ti-22Al-25Nb alloy. J. Alloys Compd. 2014, 600, 215-221. [CrossRef] 
30. Mendes, M.W.D.; Ágreda, C.G.; Bressiani, A.H.; Bressiani, J.C. A new titanium based alloy Ti-27Nb-13Zr produced by powder metallurgy with biomimetic coating for use as a biomaterial. Mater. Sci. Eng. C 2016, 63, 671-677. [CrossRef] [PubMed]

31. ISO 10993-5. Biological Evaluation of Medical Devices-Part 5: Tests for Cytotoxicity: In Vitro Methods; American National Standards Institute: Arlington, VA, USA, 1999.

32. Samal, C.P.; Parihar, J.S.; Chaira, D. The effect of milling and sintering techniques on mechanical properties of Cu-graphite metal matrix composite prepared by powder metallurgy route. J. Alloys Compd. 2013, 569, 95-110. [CrossRef]

33. Wen, M.; Wen, C.E.; Hodgson, P.; Li, Y.C. Fabrication of Ti-Nb-Ag alloy via powder metallurgy for biomedical applications. Mater. Des. 2014, 56, 629-634. [CrossRef]

34. Li, Y.; Wen, C.W.; Mushahary, D.; Sravanthi, R.; Harishankar, N.; Pande, G.; Hodgson, P. Mg-Zr-Sr alloys as biodegradable implant materials. Acta Biomater. 2012, 8, 3177-3188. [CrossRef] [PubMed]

35. Wang, B.L.; Li, L.; Zheng, Y.F. In vitro cytotoxicity and hemocompatibility studies of Ti-Nb, Ti-Nb-Zr and Ti-Nb-Hf biomedical shape memory alloys. Biomed. Mater. 2010, 5, 044102. [CrossRef] [PubMed]

36. Robin, A.; Carvalho, O.A.S.; Schneider, S.G.; Schneider, S. Corrosion behavior of Ti-xNb-13Zr alloys in Ringer's solution. Mater. Corros. 2015, 59, 929-933. [CrossRef]

37. Robin, A.; Carvalho, O.A.S. Influence of $\mathrm{pH}$ and Fluoride Species on the Corrosion Behavior of Ti-xNb-13Zr Alloys in Ringer's Solution. Adv. Mater. Sci. Eng. 2013, 1, 1-10. [CrossRef]

(c) 2018 by the authors. Licensee MDPI, Basel, Switzerland. This article is an open access article distributed under the terms and conditions of the Creative Commons Attribution (CC BY) license (http://creativecommons.org/licenses/by/4.0/). 